\title{
GIRL HELPERS AND TIME ALLOCATION OF NURSING WOMEN AMONG THE TOBA OF ARGENTINA
}

\author{
Riley B. Bove, Claudia R. Valeggia, and Peter T. Ellison \\ Harvard University
}

\begin{abstract}
In this paper we outline the activities of young girls in a Toba community of northern Argentina and examine the effect of girl helpers on time allocation of nursing women. Activity budgets were obtained for 41 girls aged 3 to 15 using spot observations. Girls spent substantial portions of observations engaged in helping behaviors. Individual values varied with age, anthropometric characteristics, and birth order. Activity budgets of 21 nursing women were obtained through focal observation sessions. Women living in households with girls aged 7 to 15 allocated $17 \%$ less time to domestic work and $9 \%$ more time to socializing during afternoon observation sessions. For nursing women in this community, direct childcare (provided by the infant's own mother) seemed to be a priority. Living with a girl helper did not have any measurable effect on the frequency or duration of nursing, or on the time that women spent caring for their infants. Based on these findings, hypotheses are outlined for future work on the effect of girl helpers on women's fertility.
\end{abstract}

KEY WORDS: Allomothering; Childcare; Helper at the nest; Time allocation; Toba

A primary function of "helping at the nest" in human societies is to relieve the bottleneck placed on women's productive and reproductive activities. Behavioral studies suggest that women's and helpers' roles are mutually

Received August 30, 2000; accepted pending revision December 7, 2000; revised version received March 14, 2002.

Address all correspondence to Riley Bove, Department of Anthropology, Harvard University, Cambridge, MA 02138. Email: riley_bove@post.harvard.edu

Copyright 2002 by Walter de Gruyter, Inc., New York Human Nature, Vol. 13, No. 4, pp. 457-472.

$1045-6767 / 01 / \$ 1.00+.10$ 
exclusive and that this interrelationship varies according to localized constraints on women's time allocation (Minturn and Lambert 1964). Peacock (1985) observed that Efe women with subadult helpers spent less time working and caring for their children and more time in leisure activities than women without girl helpers. In fact their activity budget was similar to that of women living without any dependent children, suggesting that girl helpers might reduce some of the costs to women of having children (Caldwell 1983; Lee and Bulatao 1983; Turke 1988). However, little is known about the behavioral mechanisms through which women effectively "recycle" the contributions of older daughters in the household into the production of more offspring (Crognier et al. 2001; Turke 1987).

Certain reproductive states further constrain the trade-offs that women face between their productive and reproductive activities (Hill and Hurtado 1996). It is likely that the benefits of having helpers are heightened while women are pregnant or lactating. Studies linking behavioral modifications-either of workloads (Ellison 1995; Lunn et al. 1984; Worthman et al. 1993) or of nursing patterns (Wood 1994) — to altered duration of postpartum infecundity in nursing women suggest a possible behavioral pathway through which girls' contributions might alter the duration of interbirth intervals and, hence, the fertility of mothers. To our knowledge no studies have used naturalistic observations of nursing women to study the effect of alternative helpers both on their activities and on their nursing behavior.

In this study we examine whether the presence of young helpers alters the workload and caretaking patterns of adult women in a Toba community in northern Argentina. Since preliminary work in this community (Valeggia, unpublished data) has shown that young boys are not expected to help, either in household chores or in childcare, we focused our analysis on girl helpers. Girls' helping behavior may include involvement in domestic work (e.g., cooking, cleaning, tending the fire, washing), economic work (e.g., weaving baskets, selling handicrafts), or child caretaking. After describing time allocation for Toba girls, we examine the hypothesis that women who live with girl helpers have different time budgets than women who do not live with girl helpers. Help could be translated into allowing the nursing mother to perform more economic or domestic work, or to devote more time to infant care.

Until very recently, little was known about the demography and population biology of the Toba and other ethnic groups inhabiting the Gran Chaco region of Argentina. The Chaco Area Reproductive Ecology (C.A.R.E) Project is aimed at understanding how the environment, both physical and social, interacts with reproductive biology to determine the fertility patterns observed in women of the Gran Chaco region. This study, as part of the C.A.R.E project, attempts to lay the groundwork for future 
inquiries on how changes in behavior (e.g., helping behavior in girls), particularly in the context of wider sociocultural transitions, might translate into reproductive patterns and fertility outcomes.

\section{METHODS}

\section{Study Population}

We conducted this study in NamQom, a Toba settlement of 2,000 people in the Argentine Chaco, between June and August 1997. NamQom is located $11 \mathrm{~km}$ west of the city of Formosa $\left(58^{\circ} 12^{\prime} \mathrm{W}, 28^{\circ} 10^{\prime} \mathrm{S}\right)$. Although historically hunter-gatherers, these Toba rely primarily on the wage labor of men for their subsistence. Women's activities include household chores, child caretaking, and basket weaving. Some women sell wild herbs or weavings door-to-door in Formosa, and a few are employed as cooks, teaching assistants, or housemaids. A consideration of the age structure of the population shows that NamQom is a center of migration between rural settlements and urban and agricultural employment opportunities (UNICEF 1996).

The Toba are monogamous and live in extended family units, with an average of 5.76 people per household (UNICEF 1996). Couples usually move into their own dwelling when their first or second child is born, but the woman and child return to her mother's house should the couple separate. Child fostering to female relatives is common. A previous study in this community (unpublished) showed that $77 \%$ of children born to unmarried mothers (usually adolescents) were raised by their maternal grandmother and remained in the grandmother's household even if the mother moved to a new dwelling.

Women breastfeed their children on demand from birth to 2-3 years of age, or until the next pregnancy. Co-sleeping facilitates nighttime nursing. Women's average total fertility rate in NamQom is 7.8 live births, and the average interbirth interval is 28 months (Valeggia and Ellison 2001). The child mortality rate for the year 2000 was 18.6 deaths per 1000 live births (Programa NacyDef, Province of Formosa, 2001).

\section{Activity Budgets of Toba Girls}

A demographic census of the entire village was conducted at the beginning of the study. Forty-one girls aged 3 to 15 were selected for this part of the study. These girls lived in households identified as having at least one nursing woman, who was the subject of the second part of the study (see below). Nursing women were randomly selected. Birth dates and ages of girls were ascertained using identification papers and medical records 
from the health center. Permission to work with each girl was obtained from her guardian, usually her mother. After permission was granted, demographic and anthropometric data were collected. These included age of the subject; household size and presence of a child younger than 3 in the household; birth order of the girl among her mother's daughters, and among her mother's children; whether the girl had reached menarche; and whether she was currently enrolled in school. Subject's body weight was measured using a portable scale accurate to the nearest $100 \mathrm{~g}$. Height was measured with a steel tape against a wall, accurate to within $0.5 \mathrm{~cm}$. Measures of height for age (m/year) and weight for height $(\mathrm{kg} / \mathrm{m})$, both of which are significant in studies of child growth (Keller 1991), were calculated from the anthropometric data.

Data Collection. Twenty-three rounds of spot observations were conducted. The spot observation technique (Borgerhoff Mulder and Caro 1985; Munroe et al. 1982) was chosen over focal follows for its minimization of the "observer effect" in studies involving young children: it is less intrusive and leaves girls little opportunity to alter their behavior in anticipation of a visit or under the gaze of the observer. Two trial runs, spaced two days apart, were conducted in order to familiarize the girls with the procedure and to test the validity of the behavioral categories. The rounds of observations were carried out every other day, alternating between four time blocks that had previously been observed to reflect the daily choreography of girls' activities: schooling or morning activities (9-12 A.M.), noon meal (12-2 P.M.), schooling or afternoon chores (2-4 P.M.), and chores or more playtime (4-6 P.M.). Visits were unannounced. Each round was begun with a girl randomly selected from the sample. The order in which girls were then visited on each round was chosen at the outset of the study so as to enhance the surprise element and, especially important in this small community, to prevent the subjects from being alerted to the observer's presence.

Upon arrival at or entry into the compound, the observer recorded whatever activity the girl was engaged in. When direct observation was not possible, the subject's self-report was noted if she could be found within ten minutes and additional evidence (a witness, a job left undone) was gathered. If the subject could not be found, a third party (preferably subject's sister or mother) was consulted. When no reliable source of information was available, the entry for the subject's behavior was scored as "unknown." The observed behaviors were coded in six categories: schooling (e.g., attending school or completing homework), economic work (contribution to household income, e.g., preparing baskets for sale or traveling to the market to sell baskets and produce), domestic work (participation in household maintenance chores, e.g., sweeping, cooking, washing laundry), child caretaking (e.g., minding or grooming young children), personal ac- 
tivity (e.g., socializing, playing, grooming self), and activity unknown. Occasionally (less than $5 \%$ of the sample points) the girl was simultaneously engaged in activities from two different categories. In these cases, the "helpful" activity (includes economic work, domestic work, and childcare) was recorded so as to provide a measure of the frequency of observations in which she contributed in some manner to helping her relatives. If she was engaged in two "helpful" categories, childcare was chosen over the other two in order to provide an estimate of the total frequency of observations that girls spent caring for younger relatives.

Data Analysis. A total of 780 data points was collected. The average number of data points collected for each girl was 19 (range: 12-21). The number of data points per subject varied because sometimes the 2- to 3-hour period elapsed before all the girls had been visited, and because of absences of the subjects from NamQom (e.g., travel to other communities on social occasions). Individual activity budgets were calculated using the percentage of observations assigned to each behavioral category of the total number of observations per subject. An additional combination variable, helping, was calculated by summing the percentage of observations of domestic work, childcare, and economic work for each subject.

To study the effects of age on time allocation, the sample was divided into three age groups: $3-6(n=11), 7-11(n=15)$, and 12-15 $(n=15)$. The age cutoff of 7 years was chosen based on the age that the Toba implicitly mark as the beginning of household responsibilities. The cutoff of 12 years old was chosen because at this age all but one of the girls in the study sample had reached menarche, and according to Toba tradition, at this stage girls should be fully familiar with all household chores.

Simple correlations were obtained, using Intercooled Stata 6.0, between frequency of each activity and each independent variable (dummy variables were used for noncontinuous variables; see Table 1). These descriptive statistics were favored over cause-and-effect analyses because of the exploratory focus of this part of the study and the considerable correlation among independent variables (e.g., age and menarche).

\section{Effect of Girl Helpers on Time Allocation of Nursing Women}

A sample of 21 lactating women was selected from a village-wide census. Ten women had a girl between the ages of 7 and 15 living in their household. Although younger girl helpers have been documented, 7 years of age was chosen as the downward cutoff for girl helpers since the Toba refer to this as the age at which girls take on considerable responsibilities. Fifteen was chosen as the upper cutoff age since it is the age at which the Toba celebrate their sexual maturity and is the current mean age at first birth in this community. 
Table 1. Comparison of Toba Girls' Activity Budgets by Age Group

[Mean \% observations (standard error)]

\begin{tabular}{lccccccc}
\hline & \multicolumn{7}{c}{ ACTIVITY CATEGories } \\
\cline { 2 - 7 } Age Group & Childcare & Domestic & Economic & Personal & School & Unknown & Helping* \\
\hline $3-6$ & 2.9 & 4.2 & 0.6 & 73.0 & 14.2 & 5.2 & 7.6 \\
$(n=11)$ & $(1.4)$ & $(1.3)$ & $(0.6)$ & $(4.8)$ & $(4.8)$ & $(2.1)$ & $(2.1)$ \\
$7-11$ & 14.1 & 8.1 & 1.7 & 51.8 & 20.2 & 4.0 & 35.8 \\
$(n=15)$ & $(5.4)$ & $(1.8)$ & $(1.1)$ & $(5.5)$ & $(3.9)$ & $(1.4)$ & $(6.2)$ \\
$12-15$ & 17.2 & 36.6 & 5.1 & 26.6 & 8.8 & 5.8 & 58.8 \\
$(n=15)$ & $(3.4)$ & $(3.0)$ & $(2.1)$ & $(4.2)$ & $(2.6)$ & $(1.9)$ & $(3.3)$ \\
All & 12.2 & 17.4 & 2.6 & 48.3 & 14.4 & 5.0 & 32.3 \\
$(n=41)$ & $(2.5)$ & $(2.7)$ & $(0.9)$ & $(4.0)$ & $(2.2)$ & $(1.0)$ & $(4.1)$ \\
\hline
\end{tabular}

* Sum of childcare, domestic work, and economic work.

Data Collection. Permission to visit these women in their homes was solicited. Subjects' age, parity (number of live births), marital status (single or married), nursing status (exclusive-i.e., breast milk is the only source of infant nourishment-or semi-exclusive-i.e., breast milk is being supplemented with other foods), and household size (number of people living in household) and composition (nuclear or extended) were recorded. Each subject's body weight was measured using a portable scale accurate to the nearest $100 \mathrm{~g}$. Height was measured with a steel tape against a wall, accurate to within $0.5 \mathrm{~cm}$. An additional variable, body mass index (BMI, $\mathrm{kg} / \mathrm{m}^{2}$ ), was calculated from the subject's height and weight. During a series of habituation visits, behavioral categories were verified and an $85 \%$ inter-observer reliability was reached between two observers (RBB and CRV).

Two four-hour sessions were scheduled for each woman, one in the morning and one in the afternoon, for a total of 168 hours of observation. Observations were limited to daylight hours: morning sessions were conducted from 8 A.M. to 12:30 P.M.; afternoon sessions fell between 1 P.M. and 6 P.M. The first round of observations was determined randomly, and women were not warned prior to a visit. After each woman had been observed once for a four-hour period, the observations were repeated in the same order but inverting the time period of the sessions. This allowed the same time between sessions for each woman. After allowing households to adjust to the observer's arrival for approximately 15 minutes, the women were observed continuously for the next four hours. Women's activities were recorded on a continuous basis to the nearest minute, and suckling was recorded to the nearest second. Occasionally $(5.2 \%$ of data points), women engaged in several activities simultaneously (e.g., nursing 
the baby and watching television). In those cases, the activity most relevant to the theoretical trade-off under study was recorded and an asterisk indicating multitasking was noted on the data sheet.

Data Analysis. The behavioral activities were collapsed into seven categories: care of the baby, care of other children, domestic work, economic work, personal time, social time, and "other." The percentage of observation time spent in each activity was calculated for morning and afternoon sessions, and for total observation time for each subject. The average length of bouts for each activity was also calculated. For comparison purposes, nursing variables were calculated following the protocol set forth by Vitzthum (1994): length of individual nursing bouts; time between consecutive bouts; and overall time spent nursing during the observation period. The first and last inter-bout intervals for each observation period were discarded in order to avoid truncation of these intervals (Vitzthum 1994).

Differences between women with and without girl helpers in time allocation, length of activity bouts, and nursing behavior were analyzed using independent samples $T$-test. The alpha level for statistical significance was $p<0.05$. Statistical analyses were performed using Stata Intercooled 6.0 and SPSS 10.0.

\section{RESULTS}

\section{Activity Budgets of Toba Girls}

Most girls performed at least some helping activities. Individual values for percentage of observations in which girls were engaged in helping activities ranged from $0 \%$ to $74 \%$. Among girls aged 7 to 15 , a range that captures their primary years as "girl helpers," helping and personal activities each represented approximately $40 \%$ of all observations; schooling accounted for $15 \%$ of observations and unknown activities, 5\%. A comparison of activity budgets according to time period of observation shows domestic work to be more frequent in the morning time periods, as was schooling, while personal activities were more frequent in the afternoon (see Bove 1998).

Individual activity budgets vary considerably with age. Whereas girls in the youngest (ages 3-5) group were engaged in helping activities in 5\% of the observations, girls in the oldest group (ages 12-15) were helping during almost $60 \%$ of the observations (Table 1 ).

Bivariate analyses (Table 2) indicate that age is a strong positive predictor of domestic and economic work, caretaking, and overall helping. Age is 


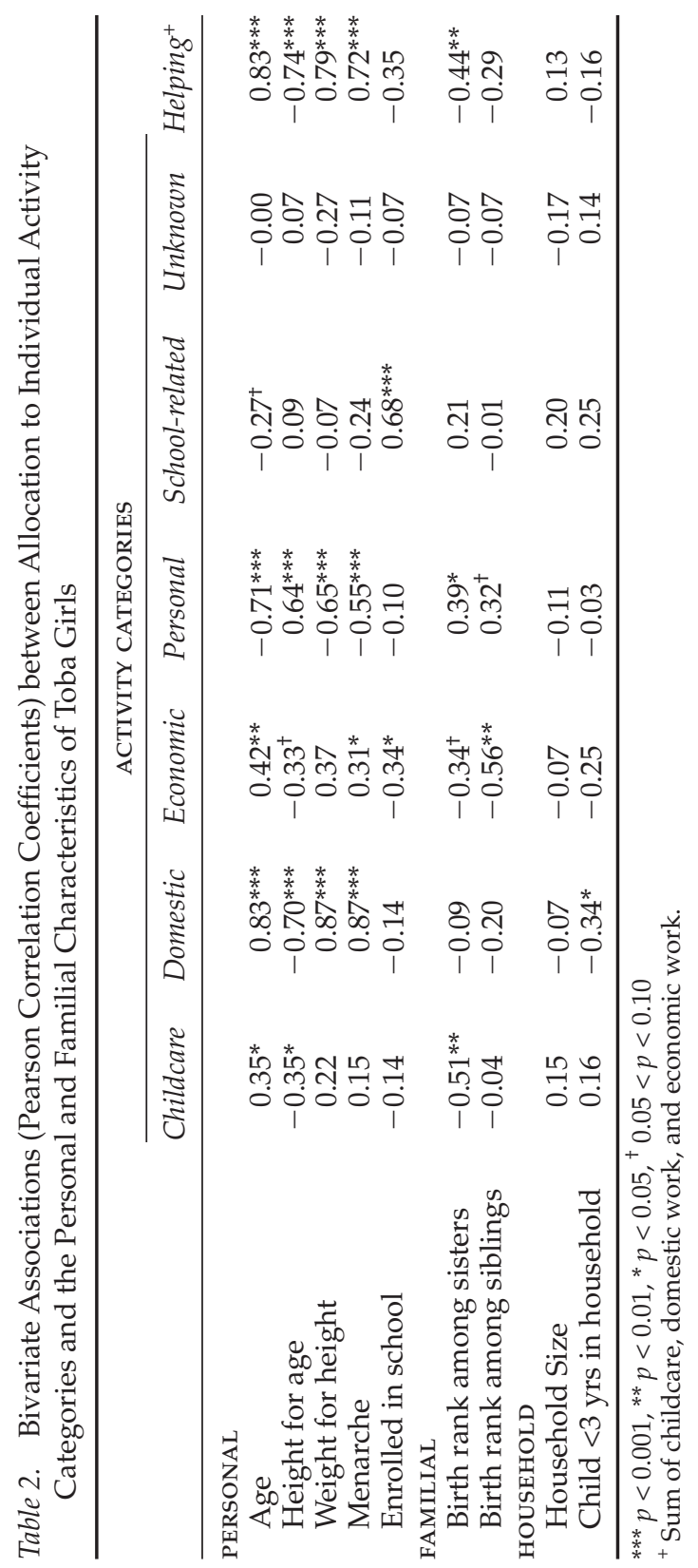


negatively associated frequency of personal and school-related activities. The activity budgets of girls varies substantially with physiological characteristics and birth order, but not with household characteristics (over $90 \%$ of the girls lived in a household with a child under the age of 3). Particularly, the percentage of observations during which helping activities were recorded was higher among subjects who were older, had reached menarche, had a higher weight-for-height, and had low birth order. The opposite is true for personal activities. Greater height-for-age is associated with less helping and more personal activities.

The information obtained during spot observations for different activities derived from various sources. Schooling was most often reported by a third party and seldom observed directly or reported by the subject. Personal activities, domestic work, and childcare were usually witnessed directly by the observer. Economic activities were slightly more likely to be reported by a third party than by direct observation or subject report (often girls accompanied older women to Formosa to help sell baskets, an activity which could not be witnessed directly).

\section{Effect of Helpers on Nursing Women's Time Allocation}

Women with girl helpers were similar to women without girl helpers in terms of personal characteristics, their baby's age and lactational status, and their household composition. Households with helpers did tend to be larger (Table 3).

Women with girl helpers spent more time in social and "other" activities and less time engaged in domestic work. Time allocated to personal activities, economic work, and caretaking of both infants and other children did not differ between women with and without girl helpers. The presence of a helper was significantly associated only with greater overall time allocation to social activities $\left(t_{(19)}=2.4, p=0.03\right)$. When the afternoon sessions were analyzed separately, there was a significant effect of the presence of girl helpers for both domestic work $\left(t_{(19)}=-2.5, p=0.02\right)$ and social activities $\left(t_{(19)}=2.1, p=0.05\right)$ (Table 4$)$. Preliminary regressions analyses run for possibly confounding variables (mother's age and parity, infant's age, and household size) showed no association with the presence of a girl helper.

With morning and afternoon sessions combined, the presence of a girl helper was associated with longer uninterrupted bouts of social activity $\left(t_{(19)}=2.3, p=0.04\right)$ but did not show a significant relationship to the lengths of bouts in any other activity. The presence of a girl helper showed no association with any of the nursing variables analyzed (all $p$ values $>$ 0.05). Multitasking (engaging in more than one activity at the same time) was infrequent and did not differ between mothers with and without helpers. 
Table 3. Sample Characteristics of Women with and without Girl Helpers

\begin{tabular}{|c|c|c|c|}
\hline & $\begin{array}{l}\text { Girl Helper } \\
\text { Present } \\
(\mathrm{n}=11)\end{array}$ & $\begin{array}{l}\text { Girl Helper } \\
\qquad \begin{array}{l}\text { Absent } \\
(\mathrm{n}=10)\end{array}\end{array}$ & Significance \\
\hline \multicolumn{4}{|l|}{ SUBJECT CHARACTERISTICS } \\
\hline Age: mean years (s.d.) & $\begin{array}{l}25.6 \\
(5.1)\end{array}$ & $\begin{array}{l}22.4 \\
(4.9)\end{array}$ & NS \\
\hline BMI: mean kg/m2 (s.d.) & $\begin{array}{l}27.0 \\
(5.2)\end{array}$ & $\begin{array}{l}23.5 \\
(2.9)\end{array}$ & NS \\
\hline Parity: mean live births (s.d.) & $\begin{array}{c}4.7 \\
(3.1)\end{array}$ & $\begin{array}{c}3 \\
(1.2)\end{array}$ & NS \\
\hline \multicolumn{4}{|l|}{ INFANT CHARACTERISTICS } \\
\hline Age: mean months (s.d.) & $\begin{array}{c}9.0 \\
(6.0)\end{array}$ & $\begin{array}{l}7.5 \\
(5.8)\end{array}$ & NS \\
\hline \multicolumn{4}{|l|}{ Sex } \\
\hline $\begin{array}{l}\text { male } \\
\text { female }\end{array}$ & $\begin{array}{l}6 \\
5\end{array}$ & $\begin{array}{l}6 \\
4\end{array}$ & NS \\
\hline $\begin{array}{l}\text { Lactational Status } \\
\text { semi-exclusive } \\
\text { exclusive }\end{array}$ & $\begin{array}{l}4 \\
7\end{array}$ & $\begin{array}{l}4 \\
6\end{array}$ & NS \\
\hline \multicolumn{4}{|l|}{ HOUSEHOLD CHARACTERISTICS } \\
\hline $\begin{array}{l}\text { absent } \\
\text { present }\end{array}$ & $\begin{array}{l}7 \\
4\end{array}$ & $\begin{array}{l}8 \\
2\end{array}$ & NS \\
\hline $\begin{array}{l}\text { Marital Status } \\
\text { not married } \\
\text { married }\end{array}$ & $\begin{array}{l}2 \\
9\end{array}$ & $\begin{array}{c}0 \\
10\end{array}$ & NS \\
\hline $\begin{array}{l}\text { Household Structure } \\
\text { extended } \\
\text { nuclear }\end{array}$ & $\begin{array}{l}5 \\
6\end{array}$ & $\begin{array}{l}2 \\
8\end{array}$ & NS \\
\hline Household Size: number of members (s.d.) & $\begin{array}{c}8.4 \\
(2.2)\end{array}$ & $\begin{array}{c}6.2 \\
(2.6)\end{array}$ & $p=0.05$ \\
\hline
\end{tabular}

\section{DISCUSSION}

In this report we have documented the involvement of Toba girls in their household and described the type of activities they engage in. We found that the presence of a girl between 7 and 15 years old is correlated with a reduction in the nursing mother's time allocated to domestic work and an increase in the mother's time spent in social activities. However, girl helpers had no effect on frequency or duration of nursing bouts. Domestic work was more frequent both for women and girls in the morning, and thus differences in the women's workloads were more apparent in the afternoons-those with help can rest while the others must continue working.

The significance of markers of physical growth and reproductive maturity in the variability of girls' activities suggests that a girl's physical and reproductive maturity are good gauges of her ability to do more demand- 
Table 4. Comparison of Time Allocation for Women with $(n=11)$ and without $(n=10)$ a Girl Aged 7-15 Living in Their Household [Mean \% observation time (s.d.)]

\begin{tabular}{|c|c|c|c|c|c|c|}
\hline \multirow[b]{2}{*}{ Activity } & \multicolumn{2}{|c|}{ MORNING SESSION } & \multicolumn{2}{|c|}{ AFTERNOON SESSION } & \multicolumn{2}{|c|}{ COMBINED SESSIONS } \\
\hline & $\begin{array}{l}\text { without } \\
\text { girl helper }\end{array}$ & $\begin{array}{l}\text { with } \\
\text { girl helper }\end{array}$ & $\begin{array}{l}\text { without } \\
\text { girl helper }\end{array}$ & $\begin{array}{l}\text { with } \\
\text { girl helper }\end{array}$ & $\begin{array}{l}\text { without } \\
\text { girl helper }\end{array}$ & $\begin{array}{c}\text { with } \\
\text { girl helper }\end{array}$ \\
\hline Domestic & $\begin{array}{l}39.0 \\
(21.4)\end{array}$ & 34.5 & $\begin{array}{l}32.3 \\
(169)\end{array}$ & $16.3^{*}$ & $\begin{array}{l}35.7 \\
(149)\end{array}$ & 25.4 \\
\hline \multirow[t]{2}{*}{ Economic } & 7.7 & 1.9 & 3.2 & 8.6 & 5.4 & 5.2 \\
\hline & $(22.8)$ & $(6.4)$ & $(10.1)$ & (19.9) & $(16.5)$ & $(10.5)$ \\
\hline \multirow[t]{2}{*}{ Care of infant } & 28.7 & 27.8 & 33.8 & 29.0 & 31.3 & 28.4 \\
\hline & $(21.1)$ & (15.6) & $(18.4)$ & $(20.6)$ & (15.0) & $(17.3)$ \\
\hline \multirow[t]{2}{*}{ Care of others } & 0.1 & 0.2 & 6.4 & 6.3 & 5.0 & 6.8 \\
\hline & $(0.1)$ & $(0.3)$ & $(5.5)$ & $(7.4)$ & $(4.0)$ & $(8.1)$ \\
\hline \multirow[t]{2}{*}{ Personal } & 10.3 & 7.2 & 11.8 & 9.7 & 11.0 & 8.4 \\
\hline & $(8.6)$ & $(7.5)$ & $(10.0)$ & (11.9) & $(7.3)$ & $(6.6)$ \\
\hline \multirow[t]{2}{*}{ Social } & 4.6 & 12.5 & 9.3 & $19.7^{*}$ & 7.0 & $16.1^{*}$ \\
\hline & $(6.7)$ & (13.9) & $(8.5)$ & $(13.7)$ & $(5.6)$ & $(10.8)$ \\
\hline \multirow[t]{2}{*}{ Other } & 4.9 & 6.1 & 3.4 & 12.2 & 4.1 & 9.1 \\
\hline & (13.3) & $(11.6)$ & $(7.6)$ & $(22.2)$ & $(7.3)$ & $(10.9)$ \\
\hline
\end{tabular}

* Statistically significant difference $(p<0.05)$

ing and dangerous tasks (e.g., tending to the fire), as well as her readiness (following social norms) to learn housekeeping and parenting skills before she is married. The negative association between height-for-age and helping is difficult to explain, as a taller girl should appear older for her age and more able to help. However, increased stature may be the result of better nutrition, which in turn may be found in households with more resources. In those households, girls' helping activities could be less needed or less substantial.

The significance of birth order in determining girls' involvement in helping-both in economic work and childcare-confirms ethnographic accounts (e.g., "boss girls"; Stack 1974) and suggests that older sisters incur more costs as a result of having younger siblings relative to other girls the same age. That birth order among sisters was important in cases where birth order among all siblings was not points to a gendered division of labor. Establishing causality in the relationship among birth order, childhood helping, childhood growth, and anthropometric measurements at age of marriage would shed light on the developmental costs and benefits of helping-in-the-nest for Toba girls.

Compounds in NamQom are close together and bound by networks of assistance and exchange, such that young girls' time allocation is determined at the level of the kinship network and not the household (see also Crognier et al. 2001). Thus while some girls with no sisters were often bound 
to their own home, other girls whose help was not instrumental in their home compound were often observed to be helping in the homes of their relatives. This might explain the lack of observed relationship between household characteristics and time allocation. The high variability in caretaking patterns, regardless of household composition, might also be attributed to an interaction between birth order and household composition so that when a younger girl is available to take care of children, older girls are graduated to domestic chores, regardless of their absolute ages. Methods of testing the hypothesis that girls with older sisters spend more time "floating" as helpers would include the comparison of records of the helpers' location throughout the day and their degree of relatedness to the head of household or nursing mother in the household where they were observed, as well as the degree of relatedness to the children that they are minding.

As documented for Hawaii (Gallimore et al. 1974), child caretaking seems to be a priority for women in NamQom even when the presence of nonmaternal caretakers reduces time allocated to domestic work. Vitzthum $(1989,1994)$ has suggested that the return of daughters from school in the afternoon might account for the different nursing patterns she observed among older Quechua women during afternoon observation sessions. Among the Toba the presence of girl helpers did not have any observable effect on women's nursing patterns. The high proportion of observations that women spent in caretaking (approximately 30\%) far exceeds the normative $10 \%$ of women's time allocated to caretaking in other cultures (Ware 1981). This devotion to infant care was further confirmed in a longer-term study of nursing and fertility by our research team, which suggested that nursing women spent on average $34 \%$ of their waking time caring for their infants (Valeggia and Ellison 2001, and unpublished data). Because of its marginalization from mainstream economic activities as well as from traditional subsistence activities, NamQom offers little opportunity for women's work outside the home, and workloads are low to moderate. Women spend, on average, $75 \%$ of their daytime either sitting or standing while leaning on something (Valeggia and Ellison 2001). In this situation domestic work, a costly task that can be delegated to helpers, might be deemed the responsive variable while caretaking of infants is the constant priority for mothers. It is likely that girls' contributions to childcare were aimed primarily at weanlings, providing them with closer attention than do the multiage sets of children who play in the wide NamQom streets. This would potentially ensure better health outcomes not of infants but of toddlers in a community with high undernutrition rates (Valeggia et al. 2002) and high mortality at weaning (23\%, Programa NacyDef 2001). Finally, women without girl helpers in their household may nevertheless rely on their husbands (Cohn et al. 2001), or on young relatives living elsewhere in the community. 
At the individual and community levels, the availability of helpers might alter mothers' psychological decisions concerning childbearing and weaning. With the guarantee of help, women might decide to have more children. They may also feel less urgency with regard to their domestic or economic tasks and therefore wean their infant later, ensuring longer interbirth intervals and better health and increased survivability of children (Alam 1995; Das Gupta 1990; Hobcraft et al. 1983; Kuate Defo 1996; Majumder 1988).

At present, indigenous communities in the Gran Chaco fall along an acculturation continuum ranging from the more traditional, living in rural, isolated areas, to the more Westernized communities, living on the periphery of most nonindigenous towns and larger cities. This variability of settlement patterns provides an opportunity for a long-term study of the role of local ecology and economics on mating structure and fertility, and on gender relations. Women's labor throughout the world depends considerably on the availability of helpers, be they daughters (Goddard 1985; Mason and Palan 1981; Robertson 1984), co-wives (Marcoux 1997), or foster "grannies" (Bledsoe and Isiugo-Abanihe 1989). In turn, labor involvement of the mother, along with other cultural and social developments such as technological innovation (Draper and Cashdan 1988), can modify girls' time allocated to schooling (Fuller and Liang 1999; Marcoux 1997) and their availability as helpers. A longitudinal study comparing the activities and contributions of girl helpers and their effects on women's energetic expenditure and fertility across different types of Toba settlements would help to bridge a substantial gap in our understanding of the effect that girls' labor has had on women's productive and reproductive function throughout human history.

Research for this project was funded by the Nestlé Foundation, the Harvard Anthropology Goelet Fund, and the Harvard College Research Program. Eduardo Fernandez-Duque commented on an early draft of this paper. We thank our anonymous reviewers for their comments on an earlier version of this paper. Our deepest appreciation goes to the women of NamQom and to their households, for their welcome and their collaboration.

Riley Bove (A.B., Harvard, 1998) is a research associate in the Department of Anthropology at Harvard University with research interests in intergenerational female networks and polygyny as a social mediator of women's health (esp. urban, African). Claudia Valeggia (Ph.D., U.C. Davis, 1996) is a postdoctoral fellow in the Department of Anthropology at Harvard University with research interests in reproductive ecology and ethnopediatry. Peter Ellison (Ph.D., Harvard, 1983) is a professor of anthropology and director of the Reproductive Ecology Laboratory at Harvard University. He is the author of On Fertile Ground: Ecology, Evolution and Human Reproduction (Harvard University Press, 2001). 


\section{REFERENCES}

Alam, N.

1995 Birth Spacing and Infant and Early Childhood Mortality in a High Fertility Area of Bangladesh: Age-Dependent and Interactive Effects. Journal of Biosocial Science 27:393-404.

Bledsoe, C., and U. Isiugo-Abanihe

1989 Strategies of Child-Fosterage among Mende Grannies in Sierra Leone. In Reproduction and Social Organization in Sub-Saharan Africa, R. J. Lesthaeghe, ed. Pp. 442-474. Berkeley: University of California Press.

Borgerhoff Mulder, M., and T. M. Caro

1985 The Use of Quantitative Observational Techniques in Anthropology. Current Anthropology 26:323-335.

Bove, $\mathrm{R}$.

1998 Mother's Helper: Girls Contribution to Childcare and Domestic Work among the Toba of Argentina. B.A. Honors Thesis, Department of Anthropology, Harvard College.

Caldwell, J. C.

1983 Direct Economic Costs and Benefits of Children. In Determinants of Fertility in Developing Countries, vol. 1, R. A. Bulatao and R. D. Lee, eds. Pp. 458-493. New York: Academic Press.

Cohn, M., C. R. Valeggia, and P. T Ellison

2001 Child Care-taking and Maternal Activities in a Toba Community, Formosa, Argentina. American Journal of Physical Anthropology (Suppl.) 32:51.

Crognier, E., A. Baali, and H. K. Hilali

2001 Do "Helpers at the Nest" Increase Their Parents' Reproductive Success? American Journal of Human Biology 13:365-373.

Das Gupta, M.

1990 Death Clustering, Mothers' Education and the Determinants of Child Mortality in Rural Punjab, India. Population Studies 44:489-505.

Draper, P., and E. Cashdan

1988 Technological Change and Child Behavior among the !Kung. Ethnology 27:339-365.

Ellison, P. T.

1995 Breastfeeding, Fertility and Maternal Condition. In Breastfeeding: Biocultural Perspectives, P. Stuart-Macadam and K. A. Dettwyler, eds. Pp. 305-345. New York: Aldine de Gruyter.

Fuller, B., and X. Liang

1999 Which Girls Stay in School? The Influence of Family Economy, Social Demands, and Ethnicity in South Africa. In Critical Perspectives on Schooling and Fertility in the Developing World, C. Bledsoe, J. B. Casterline, J. A. Johnson-Kuhn, and J. G. Haaga, eds. Pp. 181-215. Washington, D.C.: National Academy Press.

Gallimore, R. J., J. W. Boggs, and C. Jordan

1974 Culture, Behavior, and Education: A Study of Hawaiian Americans. Beverly Hills: Sage.

Goddard, V.

1985 Child Labour in Naples: The Case of Outwork. Anthropology Today 1(5): 18-21. 
Hill, K. R., and A. M. Hurtado

1996 Ache Life History: The Ecology and Demography of a Foraging People. New York: Aldine de Gruyter.

Hobcraft, J. N., J. W. McDonald, and S. O. Rutstein

1983 Demographic Determinants of Infant and Child Mortality: A Comparative Analysis. Population Studies 39:363-385.

Keller, W.

1991 Stature and Weight as Indicators of Undernutrition. In Anthropometric Assessment of Nutritional Status, J. H. Himes, ed. Pp. 113-122. New York: WileyLiss.

Kuate Defo, B.

1996 Effects of Infant Feeding Practices and Birth Spacing on Infant and Child Survival: A Reassessment from Retrospective and Prospective Data. Journal of Biosocial Science 29:303-326.

Lee, R. D., and R. A. Bulatao

1983 The Demand for Children: A Critical Essay. In Determinants of Fertility in Developing Countries, R. A. Bulatao and R. D. Lee, eds. Pp. 233-287. New York: Academic Press.

Lunn, P. G., S. Austin, A. M. Prentice, and R. G. Whitehead

1984 The Effect of Improved Nutrition on Plasma Prolactin Concentrations and Postpartum Infertility in Lactating Gambian Women. American Journal of Clinical Nutrition 39:227-235.

Majumder, A. K.

1988 Child Survival and Its Effect on Mortality of Siblings in Bangladesh. Journal of Biosocial Science 22:333-347.

Marcoux, R.

1997 Nuptialite et Maintien de la Polygamie en Milieu Urbain au Mali. Cahiers Quebecois de Demographie 26:191-214.

Mason, K. O., and V. T. Palan

1981 Female Employment and Fertility in Peninsular Malaysia: Maternal Role Incompatibility Hypothesis Reconsidered. Demography 18:549-575.

Minturn, L., and W. Lambert 1964 Mothers of Six Cultures. New York: Wiley.

Munroe, R. H., R. L. Munroe, and C. Michelson 1982 Time Allocation in Four Societies. Ethnology 22:355-370.

Peacock, N.

1985 Time Allocation, Work and Fertility among Efe Pygmy Women of Northeast Zaire. Ph.D. Dissertation, Harvard University.

Programa NacyDef (Nacimientos y Defunciones) 2001 Informe interno sobre estadísticas vitales de la Provincia de Formosa para el año 2000. Formosa, Departamento de Vigilancia Epidemológica. Ministerio de Desarrollo Humano de la Provincia de Formosa, Argentina.

Robertson, C. C.

1984 Sharing the Same Bowl: A Socioeconomic History of Women and Class in Accra, Ghana. Bloomington: Indiana University Press.

Stack, C.

1974 All Our Kin: Strategies for Survival in a Black Community. New York: Harper and Row. 
Turke, $\mathrm{P}$.

1987 Helpers at the Nest: Childcare Networks on Ifaluk. In Human Reproductive Behavior: A Darwinian Perspective, L. L. Betzig, M. Borgerhoff Mulder, and P. Turke, eds. Pp. 173-188. London: Cambridge University Press.

1988 Evolution and the Demand for Children. Population and Development Review 15(1):61-90.

\section{UNICEF}

1996 Report on the Census and Project in the Barrio NamQom. UNICEF.

Valeggia, C. R., and P. T. Ellison

2001 Lactation, Energetics, and Postpartum Fecundity. In Reproductive Ecology and Human Evolution, P. T. Ellison, ed. Pp. 85-105. New York: Aldine de Gruyter.

Valeggia, C., K. M. Faulkner, and P. T. Ellison

2002 Crecimiento en lactantes de una comunidad Toba de Formosa. Archivos Argentinos de Pediatría 100(2):31-36.

Vizthum, V. J.

1989 Nursing Behavior and Its Relation to Post-Partum Amenorrhoea in an Andean Community. Journal of Biosocial Science 21:145-160.

1994 Comparative Study of Breastfeeding Structure and Its Relation to Human Reproductive Ecology. Yearbook of Physical Anthropology 37:307-349.

Ware, $\mathrm{H}$.

1981 Women, Demography and Development. Canberra: Australian National University Press.

Wood, J. W.

1994 Dynamics of Human Reproduction: Biology, Biometry, Demography. New York: Aldine de Gruyter.

Worthman, C. M., C. L. Jenkins, J. F. Stallings, and D. Lai

1993 Attenuation of Nursing-Related Ovarian Suppression and High Fertility in Well-Nourished, Intensively Breastfeeding Amele Women in Lowland Papua New Guinea. Journal of Biosocial Science 25:425-443. 